\title{
Prostate cancer markers: An update (Review)
}

\author{
SRINIVAS PENTYALA ${ }^{1-4}$, TERRY WHYARD ${ }^{2}$, SAHANA PENTYALA $^{1}$, JOHN MULLER $^{1}$, JOHN PFAIL $^{1}$, \\ SUNJIT PARMAR ${ }^{1}$, CARLOS G. HELGUERO ${ }^{1}$ and SARDAR KHAN ${ }^{2,4}$ \\ Departments of ${ }^{1}$ Anesthesiology, ${ }^{2}$ Urology, ${ }^{3}$ Health Sciences and ${ }^{4}$ Physiology, \\ Stony Brook Medical Center, Stony Brook, NY 11794, USA
}

Received December 12, 2015; Accepted January 22, 2016

DOI: $10.3892 /$ br. 2016.586

\begin{abstract}
As the most common noncutaneous malignancy in American men, prostate cancer currently accounts for $29 \%$ of all diagnosed cancers, and ranks second as the cause of cancer fatality in American men. Prostatic cancer is rarely symptomatic early in its course and therefore disease presentation often implies local extension or even metastatic disease. Thus, it is extremely critical to detect and diagnose prostate cancer in its earliest stages, often prior to the presentation of symptoms. Three of the most common techniques used to detect prostate cancer are the digital rectal exam, the transrectal ultrasound, and the use of biomarkers. This review presents an update regarding the field of prostate cancer biomarkers and comments on future biomarkers. Although there is not a lack of research in the field of prostate cancer biomarkers, the discovery of a novel biomarker that may have the advantage of being more specific and effective warrants future scientific inquiry.
\end{abstract}

\section{Contents}

1. Introduction

2. Diagnostic and prognostic markers

3. Tissue/cell-specific detection

4. Circulating markers (blood-based diagnostics)

5. Future markers in development

6. Conclusion

\section{Introduction}

Prostate cancer is the most common noncutaneous malignancy in American men. It currently accounts for $29 \%$ of all diagnosed cancers, and ranks second as the most common cause

Correspondence to: Dr Srinivas Pentyala, Department of Anesthesiology, Stony Brook Medical Center, Health Science Centre, Level 4, Room 85, 100 Nicolls Road, Stony Brook, NY 11794, USA

E-mail: srinivas.pentyala@stonybrook.edu

Key words: prostate cancer, biomarkers, Gleason scores, metastasis, prostatectomy of cancer fatality in American men, accounting for $13 \%$ of all cancer fatalities (1). Recent studies have shown that 220,800 men in the United States were diagnosed with prostate cancer, and 27,540 men in the United States succumbed to prostate cancer (2).

Approximately $98 \%$ of prostate cancer cases are glandular in origin (3); the microscopic diagnosis of prostate adenocarinoma is based primarily on certain features of glandular formation and pattern. The most accepted and used grading protocol is the Gleason score; using this classification, prostate adenocarcinoma can be stratified on a histological basis to provide significant prognostic information for urologists. Prostate cancers are also multifocal in nature; the majority have an average of at least two geographically distinct foci of varying histological patterns and thus differing Gleason scores.

Prostatic cancer is rarely symptomatic early in its course, as the majority of malignancies arise in the peripheral portion of the gland away from the prostatic urethra. Symptomatic presentation often implies local extension or even metastatic disease. As the cancer begins to involve the urethra and/or bladder neck, obstructive voiding symptoms often develop; these can include hesitancy, slowing of the urinary stream and intermittent flow. Irritative voiding symptoms, like frequency and urgency, may also occur although these are more difficult to attribute to cancer, as they are also associated with benign prostatic hyperplasia (BPH). With tumor progression, patients may also notice sexual symptoms such as hematospermia and/or decreased ejaculatory volume secondary to ejaculatory duct obstruction. Erectile dysfunction may also be observed if there is local encroachment on neurovascular bundles.

Bony pain is often a sign of metastatic involvement of the skeleton; human prostate cancer is one of the rare cancers that repeatedly produces osteoblastic metastases to the bone in $95 \%$ of cases (4). Other signs of metastasis include anemia secondary to bone marrow involvement and lower body edema due to obstruction of local lymphatics and veins. However, in the last 15 years, the percentage of patients presenting symptoms has decreased in proportion to the patients diagnosed with prostate cancer largely due to the use of prostate specific antigen (PSA) screening.

\section{Diagnostic and prognostic markers}

Prostatic acid phosphatase (PAP). In terms of biochemical markers, the first to be used routinely in the diagnosing 
and staging of prostate cancer was PAP. PAP hydrolyzes esters under acidic conditions to yield inorganic phosphates. Although identified in numerous organs such as the liver, brain and lungs, the highest concentration of PAP is identified in the prostate. Prostate epithelial cells secrete PAP into the glandular lumen and can be measured by either immunoassay or enzymatic assay.

A 1938 study showed PAP to be elevated in the prostates of patients with metastatic prostate cancer (5). However, a subsequent study showed that PAP levels in prostate cancer tissue were only a fraction of those identified in patients with BPH (6). Furthermore, in a study that evaluated PAP levels in 102 patients, $84 \%$ of patients that had elevated PAP levels were subsequently found to have either extracapsular extension or metastatic disease (7). One study estimated that the probability of having surgically curable disease in patients with elevated PAP could be as low as 5\% (8). With the advent of serum PSA testing, PAP level evaluation has become decreasingly informative. In a study involving 460 consecutive patients referred to Johns Hopkins (Baltimore, MD, USA) (9), PAP was found to be elevated in only $4.6 \%$ patients and provided useful staging information beyond that available from PSA measurements in only $0.9 \%$ of cases.

PSA. PSA, or human kallikrein $3(\mathrm{hK} 3)$ is a $33-\mathrm{kDa}$ serine-protease of the tissue kallikrein family that was identified in prostatic extracts in the 1970s (10). PSA was discovered in human sera by Wang et al (11) and later isolated from prostate tissue by Papsidero et al (12). PSA is primarily produced by the ductal and acinar cells of the prostatic epithelium, as well as male periurethral glands, and is secreted into seminal fluid; its physiological function is to liquefy seminal coagulum in the human ejaculate (13). PSA is produced by normal, hyperplastic and neoplastic prostate tissue; however, the highest concentrations are identified in the prostatic transition zone of $\mathrm{BPH}$ patients (14). The majority of PSA circulates in serum while bound to protease inhibitors, such as $\mathrm{a}_{1}$-antichymotrypsin and $\mathrm{a}_{2}$-macroglobulin, whilst the remaining PSA exists unbound or free. Processes, such as inflammation, hyperplasia and neoplasia, within the prostate lead to disruption of physiological barriers and increased basement membrane permeability and thus increased release of PSA into the circulation (15).

PSA is widely used to screen for prostate cancer. PSA screening is less expensive than transrectal ultrasound (TRUS), and it can detect more prostate cancers than digital rectal examination (DRE) or TRUS, and is more likely to be organ-confined compared to those cancers discovered by DRE alone (16-18). The current percentage of prostate cancers that are organ-confined is estimated to be $70-80 \%$; this is compared to $20-30 \%$ prior to the use of PSA screening $(19,20)$. However, it is not recommended to use PSA alone in screening for prostate cancer as this results in missing $18-28 \%$ cancers that would have been otherwise detected if using a cutoff PSA of $4 \mathrm{ng} / \mathrm{ml}$ in conjunction with DRE (20).

The analysis of multiple preoperative variables to predict the ultimate pathological stage of patients undergoing radical prostatectomy was first developed by Oesterling et al (21) in 1987, using PAP, Gleason score and clinical stage. Subsequently, PSA-based algorithms such as those developed by Partin et al and Blute et al (22-24) used the combination of Gleason score, clinical stage and serum PSA to predict organ-confined disease (with a concordance index of 0.76) and node-positive disease (with a concordance of 0.84). These algorithms aid urologists and patients in making decisions regarding definitive surgery by estimating disease recurrence following prostatectomy.

Although certain studies showed that PSA expression in prostate cancer tissue decreased with increasing Gleason score, serum PSA levels remained proportional to the volume, Gleason score and stage of the prostate cancer $(25,26)$. This increase in serum PSA may be explained by an increased release of PSA secondary to increased disorganized prostatic epithelium in higher grade cancers. A multi-institutional study (22) involving $>4,000$ patients confirmed the linear association between PSA levels and tumor stage. While only $9 \%$ of patients with PSA $>50 \mathrm{ng} / \mathrm{ml}$ had organ-confined disease, $64 \%$ patients with PSA $<4 \mathrm{ng} / \mathrm{ml}$ had organ-confined disease.

Although PSA is the most popular biomarker for prostate cancer, it is one of the most controversial. A recent study recognized the disadvantage of PSA for the early detection of prostate cancer. It was found that multiple men must be screened, biopsied and diagnosed to prevent one fatality (27). This study sought to increase the specificity of screening for lethal prostate cancer at an early stage. The results suggested that screening for prostate cancer using PSA in men at ages 50-60 years should focus on those with PSA levels in the top quartile. It was noted that men in this group compromised the majority of subsequent cases of metastasis. Furthermore, it was recommended that men with elevated PSA levels should be tested for four kallikrein markers in order to aid in biopsy decision-making. This is one of numerous studies attempting to identify a way to increase the accuracy of PSA screening. The vast amount of literature on this subject has resulted in a number of differing opinions on the correct use of PSA and thus a more reliable marker is suggested.

$h K 2 . \mathrm{hK} 2$ is a member of the same family as PSA and exhibits $\sim 80 \%$ homology in the amino acid sequence with PSA. Similar to PSA, the highest level of hK2 is in prostatic tissue (28). As opposed to PSA, hK2 exists mostly in a free, unbound state in the serum. In patients with PSA levels between 4 and $10 \mathrm{ng} / \mathrm{ml}$, a higher percentage of free PSA (fPSA) signifies that the elevation in total PSA was more likely to be due to BPH and not cancer (29). Partin et al (30) reported that higher hK2 levels associated with lower fPSA levels increased the probability of identifying prostate cancer. In particular, in men with fPSA $<25 \%$ and an hK2/fPSA ratio $>0.18$, there was an increase of $13-62 \%$ in the detection of prostate cancer. A later study (31) compared the preoperative levels of hK2 and PSA in patients that underwent prostatectomy; the sensitivity and specificity of hK2 in detecting organ-confined disease were 37 and $100 \%$, respectively, compared to a sensitivity and specificity of 14 and $100 \%$, respectively, for total PSA.

A recent study reported on the use of a porous silicon antibody immunoassay platform for the detection of serum levels of total hK2 (32). This more effective method uses $15 \mu 1$ of serum with a total assay time of $\sim 3 \mathrm{~h}$. It has been reported that either the level of $\mathrm{hK} 2$ alone or in combination with PSA may improve the prediction of prostate cancer. This new system could contribute to future clinical practice by allowing a more accurate diagnosis of prostate cancer. 
Insulin-like growth factor-1 (IGF-1) and insulin-like growth factor binding proteins (IGFPBS). IGF-1 and IGFBPs are associated with tumor prognosis and progression in patients with colon, breast, lung and prostate cancers (33). While an early study (34) showed that IGF-1 was detectable in prostate cancer and could be used adjunctively with PSA in early detection protocols, another study (35) could not find any association between systemic IGF-1 levels and the presence of prostate cancer.

However, plasma concentrations of IGFBP-2 and IGFBP-3 were associated with disease progression; IGFBP-3 was found to be lowest in patients with bony metastasis, progressively higher in patients with localized disease and highest in healthy subjects (36). Conversely, higher levels of IGFBP-2 were associated with organ-confined disease and lower levels were associated with disease progression (33).

Transforming growth factor- $\beta 1$ (TGF- $\beta 1)$. The cytokines in the TGF- $\beta 1$ family of polypeptides have been implicated in numerous steps of tumor development and elevated levels of TGF- $\beta 1$ have been found in patients with various cancers (37). Specific immunohistochemical studies have demonstrated increased expression of TGF- $\beta 1$ in neoplastic prostatic epithelium when compared to normal prostate tissue (38). A number of studies $(39,40)$ have documented the positive correlation between elevated plasma levels of TGF- $\beta 1$ and prostate cancer progression. In another study (41), no correlation was identified between plasma levels of TGF- $\beta 1$ and prostate cancer stage, but a direct correlation was demonstrated between urinary levels of TGF- $\beta 1$ and prostate cancer stage. In a study conducted by Shariat et al (42), the preoperative plasma levels of TGF- $\beta 1$ were measured in 302 consecutive patients who underwent radical prostatectomy for clinically localized disease. The study reported that TGF- $\beta 1$ plasma levels were significantly elevated pre- and postoperatively in patients shown to have extraprostatic extension, seminal vesicle involvement and metastasis to lymph nodes.

Interleukin-6 (IL-6). IL-6 has a role in various cellular activities, including regulation of immune function and bone turnover. Studies using immunohistochemistry have demonstrated that protein concentrations of IL- 6 are increased 18 -fold in localized prostate cancer tissue when compared with normal prostate cancer tissue. In addition, concentrations of IL-6 receptors are increased 8-fold in prostate cancer tissue when compared with normal tissue (43). Another study measured the plasma levels of IL-6 and IL-6 soluble receptor in 120 consecutive patients with clinically localized prostate cancer that underwent prostatectomy (44). Plasma IL-6 levels were highest in those patients with metastatic cancer; IL-6 soluble receptor levels were highest in those with bone metastases, followed by those in patients with regional lymph node involvement. A previous study that evaluated TGF- $\beta 1$ levels also assessed the pre- and postoperative plasma levels of IL-6 and IL-6 receptor in a group of 302 patients with localized disease undergoing prostatectomy (39). Preoperative circulating levels of IL-6 and its receptor were associated with tumor volume and metastasis to lymph nodes, and levels of these two markers were decreased significantly following prostatectomy, regardless of whether cure was achieved.
Reverse transcriptase-polymerase chain reaction ( $R T-P C R)$. $\mathrm{PCR}$ is a molecular technique that amplifies minute amounts of DNA using sequence-specific primers and heat-stable bacterial DNA polymerase. When RNA is the starting material, reverse transcriptase is used to transcribe it into DNA prior to initiating the reaction. RT-PCR is extremely sensitivity in detecting tissue-specific mRNA of tumor markers such, as PSA (45), hK2 (46), and more recently, prostate-specific membrane antigen (PSMA).

PSMA is a $100-\mathrm{kDa}$ transmembrane glycoprotein identified in all types of prostatic tissue, but particularly elevated in carcinomas. PSMA levels have been used (47) to detect prostate cancer cells in the blood using RT-PCR and other modalities that employ radionuclide tagging (ProstaScint). However, another study (48) reported the detection of high PSMA mRNA levels in healthy donor bloods via RT-PCR. Further studies are required to assess the utility of using PSMA in the detection of prostate cancer.

Fatty acid synthase (FAS). Epstein et al (49) first studied the immunohistochemical staining for oncoantigen 519 (OA-519), an FAS in radical prostatectomy specimens, and suggested that OA-519 staining provided predictive information regarding pathological stage, beyond that provided by Gleason scores. In another study (50), 99 primary prostate cancer specimens were evaluated for OA-519 reactivity and the patients were followed for a mean of 4 years for disease progression. Patients who were positive for OA-519 reactivity were more likely to progress than their OA-519 negative counterparts, and furthermore, in patients with low to intermediate Gleason scores 2-7, OA-519 reactivity was shown in multivariate analyses to be the only significant predictor of cancer progression. Another study (51) examined frozen-needle prostate biopsies and identified that FAS signaling increased in the intensity from low-grade prostatic intraepithelial neoplasia (PIN) to highgrade PIN and to the highest intensity in invasive carcinoma. In addition, higher FAS signaling was associated with a higher proliferative index. The study proposed that FAS expression is an early event in the development of prostate cancer and may be used as a general prostate cancer marker.

Early prostate cancer antigen (EPCA). EPCA, a nuclear structural protein associated with prostate cancer, was identified (52) via immunohistochemistry to be expressed throughout the prostate in individuals with prostate adenocarcinoma. In a study involving 25 patients who had previously negative prostate biopsies and later found to have prostate cancer, EPCA staining intensity was assessed in the negative biopsy specimens, the subsequent positive biopsy specimens, and the eventual prostatectomy specimens. EPCA staining was found to have an $84 \%$ sensitivity and $85 \%$ specificity in detecting prostate cancer. The study suggest that EPCA immunohistochemistry has the potential to detect prostate cancer 5 years earlier than current protocols, as well as limit the number of biopsies performed as a result of increased PSA levels.

Secretory markers (urine-based diagnostics). In a study by Bolduc et al (53), it was found that urinary PSA may have potential in contributing to the differential diagnosis of prostate cancer and BPH. In particular, serum PSA levels between 
2.5 and $10 \mathrm{ng} / \mathrm{ml}$, and a low urinary PSA to serum PSA ratio are associated with prostate cancer.

Other promising research involves glutathione s-transferase (GSTP), a cytosolic enzyme that converts certain toxic compounds to glutathione (54). The detection of GSTP1 methylation in urine has shown potential as a biomarker in the diagnosis of prostate cancer. The methylation of GSTP may help distinguish patients with $\mathrm{BPH}$ from those with prostate cancer by improving the specificity of PSA.

A novel protein that has shown much evidence in the diagnosis of prostate cancer is PCA3. Multiple studies (55-57) have proven PCA3 to be a useful marker that can be used alongside PSA and DRE for a more accurate diagnosis, mainly due to its increased specificity (58). One study (59) suggests that as the PCA3 score appears to differentiate based on tumor volume and Gleason score, it may be used to select men with low-grade or low-volume cancer for clinical purposes and further research. Furthermore, PCA3 urine tests have been shown to improve specificity in prostate cancer diagnosis, and may help lower the number of prostate biopsies performed on individual patients (60). Although PCA3 has been useful as a diagnostic marker, it does not appear to have any prognostic value (61).

The analysis of multiple urinary proteins, rather than one specific protein, is also a novel idea. Instead of simply studying PSA or PCA3 levels, it has been proposed that combinations of proteins, such as TMPRSS2-ERG and PCA3, be analyzed for early detection (62). Laxman et al (63) suggest using a multiplex biomarker analysis of urine involving proteins such as golgi phosphoprotein 2 and serine protease inhibitor Kazal-type 1, as well as PCA3, to help detect prostate cancer in its early stages.

\section{Tissue/cell-specific detection}

Combining mulitple genes used as biomarkers, such as GalNac-T3, PSMA, hepsin and PCA3, in RT-PCR analysis can be a powerful new method to distinguish between prostate cancer and BPH (64).

Prostasomes have also recently been linked to the incidence of prostate cancer. A previous study has shown that malignant prostate cancer cells produce and secrete prostasomes (65). Secretion of prostasomes by prostate cancer cells is problematic (66) as they promote angiogenesis by producing and overexpressing tissue factor (67). Therefore, it is possible that monitoring the amount of prostasomes can be used as a potential marker to detect the presence of cancerous tissue.

\section{Circulating markers (blood-based diagnostics)}

While the PSA test is the current standard in blood-based diagnostic tests for prostate cancer, research is currently being performed to find an alternative and improved blood-based diagnostic test.

Chavarro et al (68) compared fatty acid levels in the blood to the risk of prostate cancer. Increased levels of trans-fatty acid in the blood is associated with nonaggressive prostate tumors, and increased polyunsaturated fatty acid levels in the blood are associated with a reduced risk of prostate cancer (69). Studying the levels of fatty acids within the blood can therefore be used as potential biomarkers in the prognosis of prostate cancer.

Gann et al (70) revealed that high levels of circulating testosterone, low levels of sex-hormone binding globulin and low levels of circulating estradiol may all contribute to an increased risk of prostate cancer, indicating that sex hormones circulating in the blood may also contribute to the occurrence of prostate cancer. However, another study reported that apart from testosterone, there is no significant correlation between the majority of sex hormones and the occurrence of prostate cancer (71). The influence of testosterone on prostate cancer is specific to the aggressive form of prostate cancer, and not the nonaggressive disease (72).

\section{Future markers in development}

The field of prostate cancer biomarkers is extensive; however, the search for a more rapid and accurate marker continues. Recent study has utilized genomic testing as a biomarker for aggressive prostate cancer. A recent discovery of the long noncoding RNA SChLAP1 in the prostate has provided a novel biomarker that not only adds to the ability to identify prostate cancer, but also to conventional risk stratification (73). SChLAP1 has been clinically validated for the prognosis of aggressive prostate cancer and integration of genomic tests may advance the diagnosis of prostate cancer through early identification of high-risk patients.

Exosomes have proved to be non-invasive cancer biomarkers as tumor-specific molecules can be found in exosomes isolated from biological fluids. A recent study has explored the proteome of urinary exosomes by utilizing mass spectrometry to identify proteins that are expressed differentially in prostate cancer patients (74). The study found that when comparing normal and prostate cancer samples of urinary exosomes, 246 proteins were differentially expressed. Of these, 221 were upregulated in exosomes from the prostate cancer patients. Although a number of the proteins exhibited high specificity and sensitivity as individual biomarkers for prostate cancer, when combined in a multi-panel test they had the potential for full differentiation of prostate cancer from non-disease controls. In conclusion, this study presents the potential of using urinary exosomes in the diagnosis and clinical management of prostate cancer.

\section{Conclusion}

The present review explored a portion of current and future biomarkers used in the detection of prostate cancer. A study from 1938 showed PAP to be elevated in the prostates of patients with metastatic prostate cancer, thus identifying the first biomarker used routinely in diagnosing and staging of prostate cancer. In the 1970 s, PSA, also known as hK3, was discovered and today it remains the most widely used, and controversial, biomarker in prostate cancer.

The search for a more rapid, specific marker for the detection of prostate cancer has lead to numerous laboratories examining biomarkers. Although a number of markers have been acknowledged, there is yet to be one that is widely accepted and used. Research now concentrates on genomic factors. For example, SChLAP1 has been validated for the 
prognosis of aggressive prostate cancer and it is suggested that the integration of genomic tests may advance the diagnosis of prostate cancer through early identification of high-risk patients. Furthermore, the potential of using urinary exosomes in the diagnosis and clinical management of prostate cancer has been explored. Understanding the biochemical and genetic aspects of prostate cancer biomarkers not only has the ability to more efficiently detect prostate cancer, but it may also provide an insight into how and why prostate cancer arises, and may suggest a method to manage or even cure it.

\section{References}

1. Greenlee RT, Hill-Harmon MB, Murray T and Thun M: Cancer statistics, 2001. CA Cancer J Clin 51: 15-36, 2001.

2. American Cancer Society Report. Cancer Facts and Figures 2015. http://www.cancer.org/research/cancerfactsstatistics/ cancerfactsfigures2015. Accessed November 8, 2015.

3. Greenberg R: Does prostate cancer represent more than one cancer? In: Prostate Cancer: Science and Clinical Practice. Mydlo JH and Godec CJ (eds). Academic Press, San Diego, CA pp29-34, 2003.

4. Gohiji K and Kitazawa S: Molecular mechanism of prostate cancer invasion and metastasis. In: Prostate Cancer: Science and Clinical Practice. Mydlo JH and Godec CJ (eds). Academic Press, San Diego, CA, pp11-27, 2003.

5. Gutman AB and Gutman EB: 'Acid' phosphatase occurring in serum of patients with metastasizing carcinoma of the prostate gland. J Clin Invest 17: 473-478, 1938.

6. Heller JE: Prostatic acid phosphatase: Its current clinical status. J Urol 137: 1091-1103, 1987.

7. Bahnson RR and Catalona WJ: Adverse implications of acid phosphatase levels in the upper range of normal. J Urol 137: 427-430, 1987

8. Lowe FC and Trauzzi SJ: Prostatic acid phosphatase in 1993. Its limited clinical utility. Urol Clin North Am 20: 589-595, 1993.

9. Burnett AL, Chan DW, Brendler CB and Walsh PC: The value of serum enzymatic acid phosphatase in the staging of localized prostate cancer. J Urol 148: 1832-1834, 1992.

10. Ablin RJ, Soanes WA, Bronson P and Witebsky E: Precipitating antigens of the normal human prostate. J Reprod Fertil 22: 573-574, 1970

11. Wang MC, Valenzuela LA, Murphy GP and Chu TM: Purification of a human prostate specific antigen. Invest Urol 17: 159-163, 1979.

12. Papsidero LD, Wang MC, Valenzuela LA, Murphy GP and Chu TM: A prostate antigen in sera of prostatic cancer patients. Cancer Res 40: 2428-2432, 1980.

13. Robert M, Gibbs BF, Jacobson $E$ and Gagnon $C$ Characterization of prostate-specific antigen proteolytic activity on its major physiological substrate, the sperm motility inhibito precursor/semenogelin I. Biochemistry 36: 3811-3819, 1997.

14. Stamey TA, Yang N, Hay AR, McNeal JE, Freiha FS and Redwine E: Prostate-specific antigen as a serum marker for adenocarcinoma of the prostate. N Engl J Med 317: 909-916, 1987.

15. Tchetgen MB and Oesterling JE: The role of prostate-specific antigen in the evaluation of benign prostatic hyperplasia. Urol Clin North Am 22: 333-344, 1995.

16. Brawer MK, Chetner MP, Beatie J, Buchner DM, Vessella RL and Lange PH: Screening for prostatic carcinoma with prostate specific antigen. J Urol 147: 841-845, 1992.

17. Crawford ED, DeAntoni EP, Etzioni R, Schaefer VC, Olson RM and Ross CA: Serum prostate-specific antigen and digital rectal examination for early detection of prostate cancer in a national community-based program. The Prostate Cancer Education Council. Urology 46: 863-869, 1993.

18. Mettlin C, Murphy GP, Lee F, Littrup PJ, Chesley A, Babaian R, Badalament R, Kane RA and Mostofi FK; The Investigators of the American Cancer Society-National Prostate Cancer Detection Project: Characteristics of prostate cancers detected in a multimodality early detection program. Cancer 72: 1701-1708, 1993.

19. Catalona WJ, Smith DS, Ratliff TL and Basler JW: Detection of organ-confined prostate cancer is increased through prostatespecific antigen-based screening. JAMA 270: 948-954, 1993
20. Babaian RJ and Camps JL: The role of prostate-specific antigen as part of the diagnostic triad and as a guide when to perform a biopsy. Cancer 68: 2060-2063, 1991.

21. Oesterling JE, Brendler CB, Epstein JI, Kimball AW Jr and Walsh PC: Correlation of clinical stage, serum prostatic acid phosphatase and preoperative Gleason grade with final pathological stage in 275 patients with clinically localized adenocarcinoma of the prostate. J Urol 138: 92-98, 1987.

22. Partin AW, Kattan MW, Subong EN, Walsh PC, Wojno KJ, Oesterling JE, Scardino PT and Pearson JD: Combination of prostate-specific antigen, clinical stage, and Gleason score to predict pathological stage of localized prostate cancer. A multiinstitutional update. JAMA 277: 1445-1451, 1997.

23. Blute ML, Bergstralh EJ, Partin AW, Walsh PC, Kattan MW, Scardino PT, Montie JE, Pearson JD, Slezak JM and Zincke H: Validation of Partin tables for predicting pathological stage of clinically localized prostate cancer. J Urol 164: 1591-1595, 2000.

24. Partin AW, Mangold LA, Lamm DM, Walsh PC, Epstein JI and Pearson JD: Contemporary update of prostate cancer staging nomograms (Partin Tables) for the new millennium. Urology 58: 843-848, 2001

25. Ellis DW, Leffers S, Davies JS and Ng AB: Multiple immunoperoxidase markers in benign hyperplasia and adenocarcinoma of the prostate. Am J Clin Pathol 81: 279-284, 1984.

26. Partin AW, Carter HB, Chan DW, Epstein JI, Oesterling JE, Rock RC, Weber JP and Walsh PC: Prostate specific antigen in the staging of localized prostate cancer: Influence of tumor differentiation, tumor volume and benign hyperplasia. J Urol 143: 747-752, 1990.

27. Stattin P, Vickers AJ, Sjoberg DD, Johansson R, Granfors T, Johansson M, Pettersson K, Scardino PT, Hallmans G and Lilja H: Improving the specificity of screening for lethal prostate cancer using prostate-specific antigen and a panel of kallikrein markers: A nested case-control study. Eur Urol 68: 207-213, 2015.

28. Yousef GM and Diamandis EP: The new human tissue kallikrein gene family: Structure, function, and association to disease. Endocr Rev 22: 184-204, 2001.

29. Catalona WJ, Smith DS, Wolfert RL, Wang TJ, Rittenhouse HG, Ratliff TL and Nadler RB: Evaluation of percentage of free serum prostate-specific antigen to improve specificity of prostate cancer screening. JAMA 274: 1214-1220, 1995.

30. Partin AW, Catalona WJ, Finlay JA,DarteC, TindallDJ, Young CY, Klee GG, Chan DW, Rittenhouse HG, Wolfert RL, et al: Use of human glandular kallikrein 2 for the detection of prostate cancer: Preliminary analysis. Urology 54: 839-845, 1999.

31. Haese A, Becker C, Noldus J, Graefen M, Huland E, Huland H and Lilja $\mathrm{H}$ : Human glandular kallikrein 2: A potential serum marker for predicting the organ confined versus non-organ confined growth of prostate cancer. J Urol 163: 1491-1497, 2000.

32. Lee SW, Hosokawa K, Kim S, Jeong OC, Lilja H, Laurell T and Maeda M: Highly sensitive porpus silicon(P-Si)-based Human Kallikrein 2 (hK2) immunoassap platform toward accurate diagnosis of prostate cancer. Sens Basel 15: 11972-11987, 2015.

33. Yu H and Rohan T: Role of the insulin-like growth factor family in cancer development and progression. J Natl Cancer Inst 92: $1472-1489,2000$

34. Djavan B, Bursa B, Seitz C, Soeregi G, Remzi M, Basharkhah A, Wolfram $\mathrm{R}$ and Marberger M: Insulin-like growth factor 1 (IGF-1), IGF-1 density, and IGF-1/PSA ratio for prostate cancer detection. Urology 54: 603-606, 1999.

35. Shariat SF, Bergamaschi F, Adler HL, Nguyen C, Kattan MW, Wheeler TM and Slawin KM: Correlation of preoperative plasma IGF-I levels with pathologic parameters and progression in patients undergoing radical prostatectomy. Urology 56: 423-429, 2000.

36. Shariat SF, Lamb DJ, Kattan MW, Nguyen C, Kim J, Beck J, Wheeler TM and Slawin KM: Association of preoperative plasma levels of insulin-like growth factor I and insulin-like growth factor binding proteins-2 and -3 with prostate cancer invasion, progression, and metastasis. J Clin Oncol 20: 833-841, 2002.

37. Blobe GC, Schiemann WP and Lodish HF: Role of transforming growth factor beta in human disease. N Engl J Med 342: 1350-1358, 2000.

38. Perry KT, Anthony CT and Steiner MS: Immunohistochemical localization of TGF beta 1, TGF beta 2 , and TGF beta 3 in normal and malignant human prostate. Prostate 33: 133-140, 1997.

39. Shariat SF, Shalev M, Menesses-Diaz A, Kim IY, Kattan MW, Wheeler TM and Slawin KM: Preoperative plasma levels of transforming growth factor beta(1) (TGF-beta(1)) strongly predict progression in patients undergoing radical prostatectomy. J Clin Oncol 19: 2856-2864, 2001 
40. Adler HL, McCurdy MA, Kattan MW, Timme TL, Scardino PT and Thompson TC: Elevated levels of circulating interleukin-6 and transforming growth factor-beta1 in patients with metastatic prostatic carcinoma. J Urol 161: 182-187, 1999.

41. Perry KT, Anthony CT, Case T and Steiner MS: Transforming growth factor beta as a clinical biomarker for prostate cancer. Urology 49: 151-155, 1997.

42. Shariat SF, Kattan MW, Traxel E, Andrews B,Zhu K, WheelerTM and Slawin KM: Association of pre- and postoperative plasma levels of transforming growth factor beta(1) and interleukin 6 and its soluble receptor with prostate cancer progression. Clin Cancer Res 10: 1992-1999, 2004.

43. Giri D, Ozen M and Ittmann M: Interleukin-6 is an autocrine growth factor in human prostate cancer. Am J Pathol 159: 2159-2165, 2001

44. Shariat SF, Andrews B, Kattan MW, Kim J, Wheeler TM and Slawin KM: Plasma levels of interleukin-6 and its soluble receptor are associated with prostate cancer progression and metastasis. Urology 58: 1008-1015, 2001.

45. Seiden MV, Kantoff PW, Krithivas K, Propert K, Bryant M, Haltom E, Gaynes L, Kaplan I, Bubley G, DeWolf W, et al: Detection of circulating tumor cells in men with localized prostate cancer. J Clin Oncol 12: 2634-2639, 1994.

46. Shariat SF, Gottenger E, Nguyen C, Song W, Kattan MW, Andenoro J, Wheeler TM, Spencer DM and Slawin KM Preoperative blood reverse transcriptase-PCR assays for prostatespecific antigen and human glandular kallikrein for prediction of prostate cancer progression after radical prostatectomy. Cancer Res 62: 5974-5979, 2002.

47. Gregorakis AK, Holmes EH and Murphy GP: Prostate-specific membrane antigen: Current and future utility. Semin Urol Oncol 16: 2-12, 1998 .

48. Millon R, Jacqmin D, Muller D, Guillot J, Eber M and Abecassis J: Detection of prostate-specific antigen- or prostate-specific membrane antigen-positive circulating cells in prostatic cancer patients: Clinical implications. Eur Urol 36: 278-285, 1999.

49. Epstein JI, Carmichael M and Partin AW: OA-519 (fatty acid synthase) as an independent predictor of pathologic state in adenocarcinoma of the prostate. Urology 45: 81-86, 1995.

50. Shurbaji MS, Kalbfleisch JH and Thurmond TS: Immunohistochemical detection of a fatty acid synthase (OA-519) as a predictor of progression of prostate cancer. Hum Pathol 27 917-921, 1996

51. Swinnen JV, Roskams T, Joniau S, Van Poppel H, Oyen R, Baert L, Heyns W and Verhoeven G: Overexpression of fatty acid synthase is an early and common event in the development of prostate cancer. Int J Cancer 98: 19-22, 2002.

52. Dhir R, Vietmeier B, Arlotti J, Acquafondata M, Landsittel D, Masterson R and Getzenberg RH: Early identification of individuals with prostate cancer in negative biopsies. J Urol 171: 1419-1423, 2004

53. Bolduc S, Lacombe L, Naud A, Grégoire M, Fradet $Y$ and Tremblay RR: Urinary PSA: A potential useful marker when serum PSA is between $2.5 \mathrm{ng} / \mathrm{mL}$ and $10 \mathrm{ng} / \mathrm{mL}$. Can Urol Assoc J 1: 377-381, 2007

54. Woodson K, O'Reilly KJ, Hanson JC, Nelson D, Walk EL and Tangrea JA: The usefulness of the detection of GSTP1 methylation in urine as a biomarker in the diagnosis of prostate cancer. J Urol 179: 508-511, discussion 511-512, 2008.

55. Sokoll LJ, Ellis W, Lange P, Noteboom J, Elliott DJ, Deras IL, Blase A, Koo S, Sarno M, Rittenhouse H, et al: A multicenter evaluation of the PCA3 molecular urine test: Pre-analytical effects, analytical performance, and diagnostic accuracy. Clin Chim Acta 389: 1-6, 2008.

56. Deras IL, Aubin SM, Blase A, Day JR, Koo S, Partin AW, Ellis WJ, Marks LS, Fradet Y, Rittenhouse H, et al: PCA3: A molecular urine assay for predicting prostate biopsy outcome. J Urol 179: 1587-1592, 2008

57. Neves AF, Araújo TG, Biase WK, Meola J, Alcântara TM, Freitas DG and Goulart LR: Combined analysis of multiple mRNA markers by RT-PCR assay for prostate cancer diagnosis. Clin Biochem 41: 1191-1198, 2008.
58. Tinzl M, Marberger M, Horvath S and Chypre C: DD3PCA3 RNA analysis in urine - a new perspective for detecting prostate cancer. Eur Urol 46: 182-186, discussion 187, 2004.

59. Nakanishi H, Groskopf J, Fritsche HA, Bhadkamkar V, Blase A, Kumar SV, Davis JW, Troncoso P, Rittenhouse H and Babaian RJ: PCA3 molecular urine assay correlates with prostate cancer tumor volume: implication in selecting candidates for active surveillance. J Urol 179: 1804-1810, 2008.

60. van Gils MP, Hessels D, van Hooij O, Jannink SA, Peelen WP, Hanssen SL, Witjes JA, Cornel EB, Karthaus HF, Smits GA, et al: The time-resolved fluorescence-based PCA3 test on urinary sediments after digital rectal examination; a Dutch multicenter validation of the diagnostic performance. Clin Cancer Res 13: 939-943, 2007.

61. van Gils MP, Hessels D, Hulsbergen-van de Kaa CA, Witjes JA, Jansen CF, Mulders PF, Rittenhouse HG and Schalken JA: Detailed analysis of histopathological parameters in radical prostatectomy specimens and PCA3 urine test results. Prostate 68: 1215-1222, 2008

62. Hessels D, Smit FP, Verhaegh GW, Witjes JA, Cornel EB and Schalken JA: Detection of TMPRSS2-ERG fusion transcripts and prostate cancer antigen 3 in urinary sediments may improve diagnosis of prostate cancer. Clin Cancer Res 13: 5103-5108, 2007.

63. Laxman B, Morris DS, Yu J, Siddiqui J, Cao J, Mehra R, Lonigro RJ, Tsodikov A, Wei JT, Tomlins SA, et al: A first-generation multiplex biomarker analysis of urine for the early detection of prostate cancer. Cancer Res 68: 645-649, 2008.

64. Landers KA, Burger MJ, Tebay MA, Purdie DM, Scells B, Samaratunga H, Lavin MF and Gardiner RA: Use of multiple biomarkers for a molecular diagnosis of prostate cancer. Int J Cancer 114: 950-956, 2005.

65. Ronquist G and Nilsson BO: The Janus-faced nature of prostasomes: Their pluripotency favours the normal reproductive process and malignant prostate growth. Prostate Cancer Prostatic Dis 7: 21-31, 2004.

66. Delves GH, Stewart AB, Cooper AJ and Lwaleed BA: Prostasomes, angiogenesis, and tissue factor. Semin Thromb Hemost 33: 75-79, 2007

67. Babiker AA, Hamad OA, Sanchez J, Ronquist G, Nilsson B and Ekdahl KN: Prothrombotic effect of prostasomes of metastatic cell and seminal origin. Prostate 67: 378-388, 2007.

68. Chavarro JE, Stampfer MJ, Campos H, Kurth T, Willett WC and Ma J: A prospective study of trans-fatty acid levels in blood and risk of prostate cancer. Cancer Epidemiol Biomarkers Prev 17: 95-101, 2008

69. Chavarro JE, Stampfer MJ, Li H, Campos H, Kurth T and Ma J: A prospective study of polyunsaturated fatty acid levels in blood and prostate cancer risk. Cancer Epidemiol Biomarkers Prev 16: 1364-1370, 2007.

70. Gann PH, Hennekens CH, Ma J, Longcope C and Stampfer MJ: Prospective study of sex hormone levels and risk of prostate cancer. J Natl Cancer Inst 88: 1118-1126, 1996.

71. Platz EA, Leitzmann MF, Rifai N, Kantoff PW, Chen YC, Stampfer MJ, Willett WC and Giovannucci E: Sex steroid hormones and the androgen receptor gene CAG repeat and subsequent risk of prostate cancer in the prostate-specific antigen era. Cancer Epidemiol Biomarkers Prev 14: 1262-1269, 2005.

72. Severi G, Morris HA, MacInnis RJ, English DR, Tilley W, Hopper JL, Boyle P and Giles GG: Circulating steroid hormones and the risk of prostate cancer. Cancer Epidemiol Biomarkers Prev 15: 86-91, 2006.

73. Prensner JR, Zhao S, Erho N, Schipper M, et al: RNA biomarkers associated with metastatic progression in prostate cancer: A multi-institutional high-throughput analysis of SChLAP1. Lancet Oncol 15: 1469-1480, 2014.

74. Øverbye A, Skotland T, Koehler CJ, Thiede B, Seierstad T, Berge V, Sandvig K and Llorente A: Identification of prostate cancer biomarkers in urinary exosomes. Oncotarget 6: 30357-30376, 2015. 